Revistade
Economila
Contemporâned

\title{
AVALIAÇÃO DO REGIME DE METAS DE INFLAÇÃO NOS PAÍSES DA AMÉRICA LATINA ENTRE 2001 E 2014
}

\author{
Divanildo Triches ${ }^{a}$ \\ Guilherme Pons Fiorentin
}

\begin{abstract}
a Professor no Programa de Pós-Graduação em Economia da Universidade do Vale do Rio dos Sinos (PPGE/UNISINOS) e bolsista produtividade PQ/CNPq.

${ }^{\mathrm{b}}$ Graduado em Ciências Econômicas pela UNISINOS.
\end{abstract}

Artigo recebido em 14/12/2016 e aceito para publicação em 01/12/2017.

RESUMO: Este artigo tem como objetivo avaliar o desempenho das políticas monetária do regime de metas de inflação nos países de América Latina entre 2001 e 2014, com séries mensais. Para isso, empregou-se um modelo VEC (vetor de correção de erro) com o intuito de analisar a função de longo prazo e da função impulso-resposta. Os resultados apontaram que a adoção do sistema de metas contribui para a redução na taxa de inflação e sua volatilidade, bem como para diminuir as oscilações na taxa de crescimento do nível de atividade. Os parâmetros estimados da velocidade de ajustamento de longo prazo do índice de preços têm indicado forte reação por parte das autoridades monetárias à mudança da taxa de inflação via taxa de juros de curto prazo. Esses ajustes também são observados no nível de atividade e da taxa de câmbio para a maioria dos países, mas com menor velocidade. Tais resultados são confirmados pela função impulso resposta, ratificando, portanto, a eficácia da política monetária no controle inflacionário, sobretudo no Peru, na Colômbia e no Chile. Já no Brasil e no México, esse fato foi observado apenas no período mais recente.

PALAVRAS-CHAVE: metas de inflação; funções impulsos-resposta; países da América Latina; vetor de correção de erros.

CLASSIFICAÇÃO JEL: E50; E52; E58.

Correspondência para: Divanildo Triches

Contato: divanildot@unisinos.br 


\section{ASSESSING INFLATION TARGETING IN THE LATIN AMERICAN COUNTRIES IN THE PERIOD 2001-2014}

ABSTRACT: This paper aims to evaluate the performance of the monetary policy of inflation targeting regime in the Latin America countries from 2001 to 2014, with monthly data. For this purpose, a VEC model (vector error correction) is applied to running data to analyze the long-term function and the impulse response function. The results pointed out that the adoption of the target system has contributed to reduce the inflation rate and its volatility and the fluctuations in the rate of growth in activity level. The estimated parameters of the long-term speed of adjustment of the price index have indicated strong reaction by the monetary authorities to change inflation rate via short-term interest rate. These adjustments are also noted in the level of activity and the exchange rate for most countries, but with less level of speed. The impulse response function confirmed these results. Therefore, the monetary policy was effective to control inflation, especially in Peru, Colombia and Chile. In Brazil and Mexico, the effectiveness of monetary policy has only been observed more recently.

KEYWORDS: inflation targeting; impulse response functions; Latin America countries; vector error correction. 


\section{INTRODUÇÃO}

O sistema de metas de inflação surgiu, a partir do início da década de 1990, como uma alternativa ao regime tradicional de controle da inflação baseado na ancoragem nominal monetária e cambial. Os países pioneiros na adoção de regime de metas de inflação foram Nova Zelândia, em 1990, seguido por Canadá e Chile, em 1991, Reino Unido, em 1992, Suécia, em 1993, e Austrália, em 1994. Essa estratégia de política monetária foi seguida por outros países de economias de mercado emergentes, como a Polônia, em 1998, Brasil e México, em 1999, e África do Sul, em 2000. Ao todo são 34 países com esse tipo de regime monetário, e sete deles estão localizados na América Latina, conforme IMF (2013). Desde a adoção do regime de metas de inflação, esses países têm tido êxito no controle e na manutenção da estabilidade de preços, como mostram Fonseca et al. (2013) e Biondi e Toneto (2005). Esse novo sistema passou a ser muito influente no pensamento atual sobre a macroeconomia e a política econômica, em particular a política monetária ${ }^{1}$.

O desempenho do regime de metas de inflação tem sido um tema extensivamente pesquisado, sem, no entanto, um consenso nos meios acadêmicos, embora muitos estudos tenham mostrado resultados bastante favoráveis nos países que o adotaram, em particular aqueles de economias de mercado emergentes. Para Hebbel-Schmidt (2003), o sistema de metas de inflação para os países da América Latina teve a vantagem de reduzir a intensidade das respostas da política monetária aos choques de inflação e do produto em magnitude de forma similar aos países desenvolvidos. Esses resultados também são compartilhados por Broto (2011), Fraga et al. (2003), Gonçalves e Salles (2008) e Mishkin e Hebbel-Schmidt (2007). Fazio et al. (2014) apontam que as condições financeiras do sistema bancário, nos países com metas de inflação, são mais estáveis e menos afetadas em períodos de escassez de liquidez global. A existência de um canal de preços estáveis também é compatível com estabilidade financeira. Por outro lado, Biondi e Toneto (2005) mostram que custos de convergência da taxa de inflação para a meta são elevados, como baixo crescimento do produto, particularmente para os países em desenvolvimento.

Nesse contexto, objetiva-se avaliar o desempenho econômico do regime de metas de inflação nos países de América Latina entre 2001 e 2014, uma vez que nesse período também se observa uma elevada estabilidade macroeconômica, além de ampliar as evidências empíricas por meio da utilização de modelos econométricos

\footnotetext{
1 Para uma análise crítica das questões relacionadas aos fundamentos teóricos do sistema de metas de inflação, veja Arestis (2013), Mishkin (1999) e (2000), Masson et al. (1998), inter alia.
} 
VAR/VEC e uso da função impulso-resposta. Destaca-se a importância de investigar o regime de metas de inflação nos países da América Latina, tendo em vista a ausência de um consenso nos meios acadêmicos quanto à sua eficácia para impulsionar o crescimento econômico. Além disso, as evidências encontradas poderão contribuir com a literatura no sentido de apontar as características dos países que possam justificar os diferentes efeitos derivados de uma política monetária similar e qual o seu efetivo desempenho em termos de estabilidade e crescimento macroeconômico. Desse modo, algumas estatísticas temporais comuns, como crescimento do produto, volatilidade do câmbio, volatilidade da inflação, taxa de desemprego, serão selecionadas para avaliar desempenho econômico dos países latino-americanos antes e após a adoção do regime de metas. Os resultados mostraram que houve uma significativa redução na taxa de inflação e na sua volatilidade a partir da adoção do sistema de meta pelos países da América Latina, além de uma queda nas oscilações na taxa de crescimento do nível de atividade. Esses resultados são também corroborados pela maioria dos estudos sobre metas de inflação, como os de Broto (2011), Calani et al. (2010), Fonseca (2013), Fraga et al. (2003), Gonçalves e Salles (2008), Mishkin e Hebbel-Schmidt (2007) e Fazio et al. (2014). Salienta-se, contudo, que a redução da taxa média de inflação, no período, tenha sido um fenômeno mundial em detrimento da contração dos preços do petróleo, de outras matérias-primas e alimentos, conforme FMI (2015). Além disso, os testes econométricos e a função impulso-resposta apresentaram forte evidência em favor da eficácia da política monetária no controle inflacionário nos países com metas de inflação.

O artigo está estruturado em cinco seções, além desta introdução. A segunda faz uma revisão do regime monetário de metas de inflação e da inflação dos países da América Latina selecionados. Na terceira seção abordam-se o modelo e aspectos de estimação do modelo econométrico. A quarta trata da análise dos resultados. Por fim, na quinta seção, encontram-se as conclusões.

\section{REGIME DE METAS E A INFLAÇÃO DOS PAÍSES DA AMÉRICA LATINA SELECIONADOS}

O regime de metas de inflação caracteriza-se como um ambiente de atuação das autoridades monetárias em que anunciam oficialmente uma meta numérica para a taxa de inflação. Adicionalmente, as autoridades assumem um compromisso e reconhecimento público de que a estabilidade de preços é seu principal objetivo. As decisões de políticas monetárias são geralmente guiadas pelos desvios das previsões da inflação futura da meta anunciada. O regime de metas de inflação pressupõe a existência de instrumentos capazes de afetar a economia por meio dos mecanismos de transmissão 
monetária, como taxa de juros de mercado, taxa de câmbio, preços dos ativos e o mecanismo de confiança e expectativas ${ }^{2}$.

Para os países latino-americanos, o regime de metas de inflação tendeu a ser bastante exitoso, além de ter apresentado uma relativa dominância em relação aos sistemas monetários alternativos, como mostram Hebbel-Schmidt (2009) e Gonçalves e Salles (2008). Além disso, esse regime monetário tem apresentado maior flexibilidade na taxa de câmbio com menor efeito sobre a inflação advinda da desvalorização cambial. Outro benefício apontado por Hebbel-Schmidt (2009) é que o regime passou a dar maior estabilidade ao nível de reservas internacionais e credibilidade da política monetária. Tais resultados são também compartilhados por Ossio e Alarcón (2010) e Freitas (2009). Esse último ressalta ainda como pontos fortes a transparência e a clareza das informações transmitida pelos Bancos Centrais ao público, diminuindo significativamente a incerteza dos agentes econômicos.

Aguirre e Burdisso (2010) avaliaram a relação entre o regime de taxa de câmbio nominal e o desempenho da inflação nos países com metas de inflação, usando um painel com 22 países que adotaram esse regime de 1990 a 2006. Os resultados apontaram que a escolha da taxa de câmbio importa nos países com metas de inflação. O regime de taxa de câmbio de facto é menos flexível do que a flutuação pura, que produz uma taxa de inflação menor para os países em desenvolvimento. Tal fato é consistente em países que apresentaram alto coeficiente de passthrough. Já Calani et al. (2010) analisam se a metas de inflação foram suficientemente flexíveis para acomodar os choques externos provenientes da crise financeira internacional e a recessão de 2008 e 2009 em cinco economias latino-americanas: Brasil, Chile, Colômbia, México e Peru; e em quatro outros países: Austrália, Coreia do Sul, Indonésia e Nova Zelândia. Os resultados indicam desvios substanciais da regra de Taylor convencional estimada para a política monetária, a qual não pode ser conciliada com uma taxa de inflação esperada e com o hiato do produto. Dessa forma, a política monetária tende a apresentar uma considerada flexibilidade no esquema de metas de inflação. Os autores encontraram ainda a existência de grande heterogeneidade nas medidas das políticas monetárias e sua eficácia entres os países. Contudo, essas políticas obtiveram êxito em reduzir as tensões nos mercados monetários e cambial, e observou-se que as metas de inflação contribuíram para manter a estabilidade de preços.

2 Outros estudos sobre América Latina podem ser encontrados em Agenor e Silva (2013), Aguirre e Burdisso (2008), Calani et al. (2010), Capistrán e Ramos-Francia (2010), Fazio et al. (2014), Fonseca et al. (2013), Fraga et al. (2003), Gonçalves e Salles (2008), Ossio e Alarcón (2010) e Triches (2003). 
Broto (2011) também investigou oito países da América Latina com e sem metas de inflação, usando o modelo ARCH estrutural quadrático. Concluiu que o regime de metas, além de trazer estabilidade, reduziu o nível, a volatilidade e a persistência da inflação, bem como as incertezas macroeconômicas. Para a Colômbia, os resultados apontam que a taxa de câmbio real tem pouco efeito sobre o nível de atividades econômicas, e a inflação se manteve imune às mudanças na taxa de câmbio nominal. A consolidação do arranjo de metas de inflação tem sido positiva em manter a taxa de inflação estável sobre as atividades econômicas taxa de câmbio e estabilidade financeira, como concluem Hemann et al. (2014).

Os indicadores comparados dos regimes de metas de inflação adotados pelos países da América Latina estão reportados, sinteticamente, no Quadro 1. Nota-se que quase todos os países adotaram o novo arranjo monetário, de maneira formal, no ano de 1999, com exceção apenas do Peru, que o fez em 2002, e do Paraguai, que o fez em 2011. Quanto ao aspecto da institucionalidade, Chile, México, Peru e Paraguai declaram a independência formal da autoridade monetária. Já no Brasil e na Colômbia não há uma independência institucional, mas os bancos centrais são independentes para operar a política monetária. Em geral, a meta de inflação é definida pelo Banco Central e pelo governo desses países. No caso brasileiro, essa definição compete ao Conselho Monetário Nacional (CMN), que é composto pelo presidente do Banco Central e pelos ministros da Fazenda e do Planejamento. O objetivo declarado, por sua vez, apresenta certa conformidade entre os países, ou seja, é o de garantir um sistema financeiro sólido e uma inflação baixa e estável.

No que tange ao estabelecimento das metas, a taxa de inflação é usada, em todos os casos, como referência, a qual é medida pelo índice de preços amplos no Brasil e no Chile, com horizonte temporal anual e bianual de convergência da inflação na meta, respectivamente. Já nos demais países é utilizado o índice de preços ao consumidor com um horizonte temporal que varia de 18 meses na Colômbia a quatro anos no México. Salienta-se, contudo, que o Banco Central da Colômbia usa como guia para estabelecer a meta o núcleo do índice. Os países com horizonte temporal mais longo tendem a ter vantagem em relação àqueles com horizonte mais curto, porque um horizonte temporal mais longo permite à política monetária maior flexibilidade para suavizar os choques econômicos exógenos. 


\section{Quadro 1 - Sínteses dos indicadores dos regimes de metas dos países da América Latina}

\begin{tabular}{|c|c|c|c|c|c|c|}
\hline Indicadores & Brasil & Chile & Colômbia & México & Peru & Paraguai \\
\hline Adoção & 1999 & $\begin{array}{c}1990 / * \\
1999\end{array}$ & 1999 & 1999 & 2002 & 2011 \\
\hline $\begin{array}{l}\text { Institutional/ } \\
\text { Fixação da } \\
\text { meta }\end{array}$ & $\begin{array}{c}\mathrm{CMN} \text { e } \\
\mathrm{BC}\end{array}$ & $\begin{array}{c}\text { BC } \\
\text { Indepen. }\end{array}$ & $\begin{array}{c}\text { Governo e } \\
\text { BC }\end{array}$ & $\begin{array}{c}\text { Governo e } \\
\text { BC Indepen. }\end{array}$ & $\begin{array}{c}\text { Governo e } \\
\text { BC Indepen }\end{array}$ & $\begin{array}{l}\text { Governo e BC } \\
\text { Indepen }\end{array}$ \\
\hline Objetivo & $\begin{array}{c}\text { Estabilidade } \\
\text { dos preços e } \\
\text { do Sistema } \\
\text { financeiro }\end{array}$ & $\begin{array}{c}\text { Inflação } \\
\text { baixa e } \\
\text { estável }\end{array}$ & $\begin{array}{l}\text { Inflação baixa } \\
\text { e estável }\end{array}$ & $\begin{array}{l}\text { Estabilidade } \\
\text { da moeda e } \\
\text { do Sistema } \\
\text { financeiro }\end{array}$ & $\begin{array}{c}\text { Inflação } \\
\text { baixa e } \\
\text { estável }\end{array}$ & $\begin{array}{c}\text { Inflação baixa e } \\
\text { estável }\end{array}$ \\
\hline $\begin{array}{l}\text { Îndice de } \\
\text { referência }\end{array}$ & IPCA & IPCA & $\begin{array}{l}\text { Núcleo do } \\
\text { IPC }^{* *}\end{array}$ & IPC & IPC & IPC \\
\hline $\begin{array}{l}\text { Horizonte } \\
\text { temporal }\end{array}$ & Anual & Bianual & $\begin{array}{c}\text { Anual } \\
\text { (18 meses) }\end{array}$ & $\begin{array}{c}\text { Curto prazo, } \\
12 \text { meses } \\
\text { Longo prazo, } \\
4 \text { anos }\end{array}$ & $\begin{array}{l}\text { Em todo } \\
\text { momento }\end{array}$ & 8 trimestres \\
\hline $\begin{array}{l}\text { Inst. Política } \\
\text { Monetária }\end{array}$ & $\begin{array}{c}\text { Taxa de juros } \\
\text { Over/Selic }\end{array}$ & $\begin{array}{c}\text { Taxa de } \\
\text { juros } \\
\text { Overnight }\end{array}$ & $\begin{array}{l}\text { Taxa de juros } \\
\text { Overnight }\end{array}$ & $\begin{array}{c}\text { Regulação da } \\
\text { liquidez }\end{array}$ & $\begin{array}{c}\text { Taxa de } \\
\text { juros } \\
\text { Overnight }\end{array}$ & $\begin{array}{l}\text { Taxa de juros } \\
\text { Interbancária }\end{array}$ \\
\hline Meta atual (\%) & $4,5+/-2$ & $3,0+/-1$ & $3,0+/-1$ & $3,0+/-1$ & $2,0+/-1$ & $5,0+/-2,5$ \\
\hline $\begin{array}{l}\text { Taxa de } \\
\text { Inflação na } \\
\text { adoção (\%) }\end{array}$ & 3,3 & 3,2 & 9,0 & 9,0 & $-0,1$ & 8,3 \\
\hline$\underset{* * *}{\text { Taxa de juros }}$ & 12,00 & 2,78 & 4,5 & 3,10 & 3,5 & 6,36 \\
\hline
\end{tabular}

Notas: $\left.{ }^{*}\right)$ Informal e formal, respectivamente; ${ }^{* *}$ exclusão dos preços dos alimentos e de alguns preços administrados; $(* * *)$ em $\%$ ao ano em dez/2014

Fonte: Bancos Centrais dos países e Hammond (2012).

A meta central da taxa de inflação é de 3,0\% com intervalo de apenas um por cento para mais ou para menos, como no caso do Chile, Colômbia e México, embora a inflação observada na sua adoção estivesse acima desses parâmetros. O Peru foi o país que adotou a menor meta, com $2 \%$ e mesmo intervalo de tolerância. No outro extremo encontram-se Brasil, com 4,5\% e dois pontos percentuais de tolerância, e Paraguai, com $5 \%$ e uma variação de $2,5 \%$ para mais e para menos desse limite. O instrumento utilizado para a política monetária por Brasil, Chile e Colômbia é a taxa de juros de curtíssimo prazo (overnight). O México emprega um sistema baseado em regulação da liquidez e os saldos acumulados e o Paraguai, baseado na taxa de juros interbancária ${ }^{3}$.

3 Os Bancos Centrais tendem a ser transparentes com o público e divulgam um informe sobre a inflação quatro vezes ao ano, com exceção apenas do Paraguai, que faz duas divulgações. Todos os informes contêm as projeções da inflação. 
Destacadamente o Brasil praticava, em 2014, a maior taxa de juros dentre os países, com $12 \%$ ao ano, seguido pelo Paraguai, com 6,36\%, e pela Colômbia, com 4,5\%. No outro extremo encontram-se o Chile, com uma taxa básica de juros de $2,78 \%$ ao ano, e o México, com 3,10\%.

O comportamento e a volatilidade dos processos inflacionários experimentados pelos países da América Latina no período 1990 a 2013 estão ilustrados nas Tabelas 1 e 2. Em ambos os casos a redução foi simplesmente excepcional do período 1990-1999 para o período 2000-2007, em particular para o Peru, com queda na taxa média de inflação de 793,88\% ao ano para 2,57\%; para o Brasil, de 715,49\% para 6,40\% ao ano; e para Argentina, de 252,91\% para 9,06. Em termos de volatilidade a queda foi ainda mais expressiva de $2.408,33 \%$ para $1,76 \%$, para o primeiro caso; de $931,42 \%$ para 2,32\%, para o Brasil; e de 726,08 para 6,47, para Argentina. Para os países como Colômbia e México, a média de um período para outro passou de aproximadamente $20,0 \%$ para em torno de $5,0 \%$ ao ano.

Tabela 1 - Inflação dos países da América Latina com metas de inflação no período 1990 a 2013

\begin{tabular}{lcccc}
\hline \multirow{2}{*}{ Países } & \multicolumn{2}{c}{ 1990-1999 } & \multicolumn{2}{c}{ 2000-2013 } \\
\cline { 2 - 5 } & Média (\%) & Volatilidade & Média (\%) & Volatilidade \\
\hline Brasil & 715,49 & 931,42 & 6,40 & 2,32 \\
Chile & 10,77 & 7,45 & 3,12 & 2,30 \\
Colômbia & 21,42 & 6,27 & 5,05 & 2,27 \\
México & 20,20 & 13,48 & 4,51 & 1,69 \\
Paraguai & 15,72 & 11,21 & 7,18 & 3,70 \\
Peru & 793,88 & $2.408,33$ & 2,57 & 1,76 \\
Uruguai & 45,40 & 38,04 & 8,39 & 5,36 \\
Média & 231,84 & 488,09 & 5,32 & 2,77 \\
\hline
\end{tabular}

Fonte: CEPAL.

A redução da taxa de inflação e de sua volatilidade tende a coincidir com a adoção das metas de inflação em quase todos os países. Contudo, no Brasil a queda mais acentuada da inflação iniciou com a implementação do Plano Real em 1994. O Chile foi a economia que experimentou a menor queda da volatilidade e da taxa de inflação, que passaram de $7,45 \%$ e $10,77 \%$ ao ano no período $1990-1999$, para $2,30 \%$ e $3,12 \%$ ao ano no período 2000-2013, respectivamente. Destaca-se, no entanto, que esse país já vinha adotando o regime de metas de inflação informalmente desde 1990. A média anual dos países, em conjunto, teve uma redução da taxa de inflação de $231,84 \%$ ao longo dos anos 1990 para 5,32\% para o período subsequente. 
Considerando o grupo de países que não optou pela meta de inflação, nota-se que as taxas médias de inflação e de sua variabilidade foram praticamente o dobro daquelas registradas pelos países que aderiram ao sistema de metas de inflação. A taxa média do primeiro grupo foi de 10,06, com um desvio padrão de 7,25, contra uma média de 5,32 , com desvio padrão de 2,77 para o segundo. Esse fato parece mostrar que o arranjo monetário baseado em metas para a inflação é superior do que outros regimes adotados pelos países da América Latina.

\section{Tabela 2 - Inflação dos países da América Latina sem metas de inflação no período 1990 a 2013}

\begin{tabular}{lcccc}
\hline \multirow{2}{*}{ Países } & \multicolumn{2}{c}{ 1990-1999 } & \multicolumn{2}{c}{ 2000-2013 } \\
\cline { 2 - 5 } & Média (\%) & Volatilidade & Média (\%) & Volatilidade \\
\hline Argentina & 252,91 & 726,08 & 9,06 & 6,47 \\
Bolívia & 10,44 & 5,65 & 5,20 & 3,51 \\
Costa Rica & 16,85 & 6,30 & 9,24 & 3,19 \\
Equador & 39,04 & 12,13 & 13,87 & 25,38 \\
Guatemala & 15,27 & 12,34 & 6,33 & 2,42 \\
Panamá & 1,09 & 0,40 & 3,13 & 2,47 \\
Venezuela & 47,44 & 22,01 & 23,58 & 8,05 \\
Média & 54,72 & 112,12 & 10,06 & 7,35 \\
\hline
\end{tabular}

Fonte: CEPAL.

A evolução da taxa média anual de crescimento do produto e de sua volatilidade ao longo da década de 1990 e dos anos 2000 a 2013 é reportada nas Tabelas 3 e 4 . Percebe-se que quase todos os países que adotaram o sistema de metas de inflação apresentaram um crescimento nessa média entre 1990-1999 e 2000-2013. A exceção ficou por conta do Chile e do México, com uma queda nessas taxas de 34,5\% e 25,0\%, respectivamente. Por outro lado, os maiores crescimentos médios foram registrados pelo Brasil, que passou de $1,64 \%$ para 3,35\% ao ano em iguais períodos, o que corresponde a uma elevação de mais de duas vezes. Em seguida despontam Peru e Colômbia, com uma taxa média de crescimento do produto, por ordem, de 70,2\% e 46,0\%. Tal tendência também é observada na volatilidade da taxa de crescimento desse produto, nesse caso, a maior parte dos países mostrou uma redução, como Chile, que passou de 3,73 entre 1990-1999 para 1,85 no período de 2000-2013. Isso representa uma queda de 50,4\%. Em seguida aparecem Peru, com redução de $47,1 \%$, e Brasil, com $24,6 \%$ na diminuição da variabilidade do crescimento do produto. Já Paraguai e Uruguai, que adotaram o regime de metas de inflação mais recentemente, apresentaram comportamento oposto ${ }^{4}$.

\footnotetext{
4 No Anexo encontram as médias da taxa de desemprego, taxa de juros e taxa de câmbio.
} 
Por outro lado, para conjunto de países selecionados que não aderiram ao regime de metas de inflação, nota-se maior queda média de crescimento do produto. No período de 2000 a 2013 em relação a 1990 a 1999, foi registrada pela Argentina queda de $41 \%$ ao ano para 3,5\%. Em seguida aparecem Guatemala e Costa Rica. Em contrapartida, Equador foi o que apresentou maior crescimento médio do produto de um período para outro, com $1,2 \%$. Considerado todo o grupo dos países que não adotaram o sistema de metas de inflação, quase não houve mudança na taxa média de crescimento dos anos de 1990 para os anos de 2000. Contudo, as taxas de crescimento se mostram um pouco mais voláteis no período de 2000 a 2013.

Tabela 3 - Taxa de crescimento do produto dos países da América
Latina com meta de inflação no período 1990 a 2013

\begin{tabular}{lcccc}
\hline \multirow{2}{*}{ Países } & \multicolumn{2}{c}{ 1990-1999 } & \multicolumn{2}{c}{ 2000-2013 } \\
\cline { 2 - 5 } & Média anual (\%) & Volatilidade & Média anual (\%) & Volatilidade \\
\hline Brasil & 1,64 & 2,96 & 3,35 & 2,23 \\
Chile & 6,37 & 3,73 & 4,17 & 1,85 \\
Colômbia & 2,89 & 2,97 & 4,22 & 1,73 \\
México & 3,38 & 3,58 & 2,53 & 2,82 \\
Paraguai & 2,88 & 2,51 & 3,59 & 5,31 \\
Peru & 3,23 & 5,01 & 5,50 & 2,65 \\
Uruguai & 3,25 & 3,60 & 3,48 & 5,74 \\
Média & 3,37 & 3,48 & 3,83 & 3,19 \\
\hline
\end{tabular}

Fonte: CEPAL.

Tabela 4 - Taxa de crescimento do produto dos países da América Latina sem meta de inflação no período 1990 a 2013

\begin{tabular}{lcccc}
\hline \multirow{2}{*}{ Países } & \multicolumn{2}{c}{ 1990-1999 } & \multicolumn{2}{c}{ 2000-2013 } \\
\cline { 2 - 5 } & Média anual (\%) & Volatilidade & Média anual (\%) & Volatilidade \\
\hline Argentina & 4,1 & 5,11 & 3,5 & 6,71 \\
Bolívia & 4,0 & 1,61 & 4,1 & 1,30 \\
Costa Rica & 4,8 & 2,39 & 4,5 & 2,16 \\
Equador & 2,3 & 2,70 & 3,5 & 2,27 \\
Guatemala & 4,1 & 0,72 & 3,7 & 1,35 \\
Panamá & 5,6 & 2,67 & 6,0 & 3,66 \\
Venezuela & 2,5 & 4,83 & 3,1 & 7,31 \\
Média & 3,9 & 2,86 & 4,0 & 3,53 \\
\hline
\end{tabular}

Fonte: CEPAL. 
Na comparação entres os países com e sem metas de inflação, os dados mostram uma ligeira diferença favorável aos primeiros em termos de taxa média de crescimento, que foi de 0,46 ponto percentual contra 0,1 , quando observados os períodos de 2000 2013 e 1990-1999. Isso também é notado com relação à volatilidade das taxas de crescimento em que, para o grupo com metas, se reduziram em 0,29 e, para os países sem o regime de metas, aumentou em 0,67 nos respectivos períodos.

\section{MODELO, ESTIMAÇÃO E DEFINIÇÃO DE VARIÁVEIS}

A política monetária pode ser conduzida por meio de uma regra para a taxa de juros nominal de curto prazo. Equivalentemente, o Banco Central segue uma política de ajustamento da taxa de juro nominal com a finalidade de manter a taxa de inflação dentro de um sistema de metas preestabelecidas. A regra de taxa de juros destacada na literatura é de Taylor (1993), a qual é baseada em dois elementos: a) se a taxa de juros nominal sempre aumenta mais do que inflação, tem como consequência a elevação da taxa de juros real com aumento da inflação; b) a taxa de juros aumenta quando o produto está acima de seu valor potencial e diminui quando está abaixo desse nível. A regra proposta por Taylor é linear na inflação e no percentual de desvio do produto de sua taxa natural, ou seja:

$$
i_{t}=a+\varphi_{\pi} \pi_{t}+\varphi_{Y}\left(\ln Y_{t-} \ln Y_{t}^{n}\right)
$$

Em (1), $i_{t}$ é a taxa de juros nominal de curto prazo; $\pi_{t}$, a taxa de inflação; $Y$, o nível do produto; e $Y_{t}^{n}$, o produto potencial no período $t . \varphi_{\pi}, \varphi_{y}$ são parâmetros positivos, e $a$ mede o intercepto da equação. Assumindo que $r_{t}^{n}$ é a taxa de juros real que prevalece quando o hiato do produto é igual a zero ou $Y_{t}=Y_{t}^{n}$, então a equação (1) é equivalente a:

$$
i=r^{n}+\varphi_{\pi}\left(\pi_{t-} \pi^{*}\right)+\varphi_{Y}\left(\ln Y_{t-} \ln Y_{t}^{n}\right)
$$

Em (2), a meta de inflação ou a inflação ótima escolhida é $\pi_{t}^{*}=\left(r^{n}-a\right) / \varphi_{\pi}$. Assim, o banco central aumenta a taxa de juros real acima de seu nível de equilíbrio de longo prazo em resposta se a inflação exceder a sua meta e se o produto exceder sua taxa natural ${ }^{5}$.

\footnotetext{
Para manter a inflação baixa e a economia estável, o valor dos coeficientes da regra de Taylor seria $\varphi_{\pi}=1,5$, $\varphi_{\pi}=0,5$ e $r^{n}=\pi^{*}=2,0 \%$. Veja Romer (2013, p. 546).
} 
Para o presente caso pressupõe-se uma regra de Taylor ampliada que incorpora a taxa de câmbio. A avaliação dos efeitos e da consistência da política monetária dos países latino-americanos que adotaram a metas de inflação é feita pelo emprego do modelo do vetor autorregressivo (VAR) e com mecanismo de correção de erros (VEC). Essa categoria de modelo possibilita avaliar a influência recíproca entre as variáveis consideradas. Portanto, elas são consideradas endógenas e explicadas por seus valores defasados no tempo, como abordam Enders (2010) e Paterson (2000). A estimação, na forma generalizada, é obtida por meio de variáveis em diferença no curto prazo, mas preservam-se as informações de longo prazo de acordo com o mecanismo de correção de erros, conforme a equação (7):

$$
\Delta y_{t}=\pi_{0}+\phi y_{t-1}+\sum_{i=1}^{n} \pi_{i} \Delta y_{t-i}+\sum_{i=1}^{n} \beta_{i} \Delta x_{t-i}+\gamma_{t} D_{t}+\varepsilon_{t}
$$

Em (7), $Y_{t}$ é o vetor ( $\mathrm{n} \times 1$ ) de variáveis endógenas; $\pi_{0}$ é o vetor ( $\left.\mathrm{n} \times 1\right)$ dos termos de intercepto; $\phi$ é o vetor $\mathrm{n} \times 1$ de cointegração ou os coeficientes de ajuste de longo prazo do modelo; $\pi_{i}$ é a matriz ( $\mathrm{n} \times \mathrm{n}$ ) associada aos parâmetros das variáveis endógenas do modelo; $\beta_{i}$ é a matriz $(\mathrm{n} \times \mathrm{n}$ ) associada aos parâmetros do vetor ( $\mathrm{nx}$ 1) da variável exógena $x_{t} ; \gamma_{t}$ é a matriz ( $\mathrm{n} \times \mathrm{n}$ ) associada aos parâmetros das variáveis dummy; $D_{t}$ refere-se ao vetor $(\mathrm{n} \times 1)$ das variáveis dummy; e $\varepsilon_{t}$ é o vetor $(\mathrm{n} \times 1)$ de resíduos ou erros estocásticos, sendo que $E\left(\varepsilon_{t}\right)=0$ e $E\left(\varepsilon_{t} \varepsilon_{\tau}\right)=\sigma^{2}$, para $t=\tau$ e $E\left(\varepsilon_{t} \varepsilon_{\tau}\right)=0$, para $t \neq \tau$.

Para a estimação do modelo, o procedimento inicial é investigar a estacionariedade das séries por meio de testes de raiz unitária. Portanto, para isso são empregados os testes ADF (Augmented Dickey-Fuller) e PP (Phillips-Perron). Caso as variáveis apresentem raiz unitária, é necessário que elas cointegrem. Nesse caso, utiliza-se o teste de Johansen.

A etapa seguinte consiste em avaliar as funções de impulso-resposta que mostram como um impulso ou uma inovação numa dada variável tem efeitos sobre as demais. De acordo com Hamilton (1994), a função de impulso-resposta pode ser expressa pelas equações (9) e (10).

$$
y_{t}=\mu+\varepsilon_{t}+\Psi_{1} \varepsilon_{t-1}+\Psi_{2} \varepsilon_{t-2}+\ldots
$$

Assim, a matriz $\Psi_{S}$ pode ser interpretada:

$$
\Psi_{s}=\frac{\partial y_{t+s}}{\partial \varepsilon_{t}^{\prime}}
$$


Em (10), $\Psi_{S}$ se trata da matriz de multiplicadores dos efeitos de uma inovação ou choque sobre as variáveis endógenas. As linhas e colunas da matriz $\Psi_{S}$ captam os resultados de uma inovação $\varepsilon_{t}$ no valor da $i$-ésima variável no tempo $t+s$. O formato da função de impulso- resposta considerada é generalizado. Assim, como abordam Pesaram e Shin (1998), a ordenação das variáveis não interfere nos resultados.

No que concerne à definição das variáveis, são aquelas comumente usadas na literatura que permitem identificar o desempenho e a consistência da política monetária ${ }^{6}$. As variáveis empregadas, ao longo do período de 2001 a 2014, têm periodicidade mensal com transformação logarítmica e dessazonalizadas, as quais são: a) taxa de juros efetiva de cada país e anualizada, juros TJ; b) índice da variação mensal dos índices de preços de cada país, IP; c) Produto Interno Bruto (PIB), usado com proxy do índice industrial de produção física, com ajuste sazonal, PI; d) taxa de câmbio nominal, média mensal, câmbio, TC. As séries estatísticas foram coletadas junto ao banco central de cada país, que serve como guia para a elaboração da política monetária.

\section{DESCRIÇÃO E ANÁLISE DOS RESULTADOS}

Inicialmente procedeu-se a análise da ordem de integração das variáveis PI, TC, IP, TJ, produção industrial, taxa de câmbio, taxa de inflação e taxa de juros, respectivamente. Assim, foram empregados os testes de raiz unitária no nível, incluindo a constante e a tendência. Os resultados dos testes de Dickey-Fuller Aumentado (ADF), de Dickey-Fuller GLS, de Philip-Perron e de KSSP estão na Tabela $5^{7}$. Nota-se que em quase todas as variáveis não é possível rejeitar a hipótese da presença de raiz unitária. As exceções ficaram por conta da taxa de juros, no Brasil, em que os testes acusaram a presença de estacionariedade, e, em menor nível de significância, a taxa de câmbio, no México. Salienta-se que todos os testes indicaram ordem de integração nula em primeira diferença das variáveis, com nível de significância de $1 \%$. Isso implica aceitar a hipótese de estacionariedade das séries.

Considerando que a maioria das séries é integrada na ordem um ou I(1), por consequência torna-se necessário avaliar a possível relação de cointegração entre elas. Desse modo, a ordem do Vetor Autorregressivo (VAR) ou o número de defasagem foi identificado por meio dos critérios de informação de Schwartz (SC), de Akaike (AIC) e pela avaliação dos testes de autocorrelação residual, dados pelo multiplicador de

6 Veja os estudos de Fonseca et al. (2013), entre outros.

7 O software utilizado foi o Eviews 7.2. 
Lagrange (LM), e da heterocedasticidade, pelo teste White. Assim, a análise conjunta desses testes, levando-se em conta um nível de significância de $5 \%$, e dos critérios de informação, permitiu a seleção do modelo com duas defasagens pelo seu melhor ajuste para a Colômbia, quatro defasagens para o México, cinco defasagens para Brasil, Peru e Chile. Esse fato também é confirmado pelas raízes características, as quais estão dentro do círculo unitário.

Tabela 5 - Testes de raiz unitária com intercepto e tendência

\begin{tabular}{|c|c|c|c|c|c|c|}
\hline País/Testes & & ADF & GLS & PP & KSSP & Decisão \\
\hline & PI & $-2,793$ & $-2,617$ & $-2,890$ & 0,231 & $\mathrm{I}(1)$ \\
\hline Brasil & $\mathrm{TC}$ & $-2,103$ & $-1,629$ & $-2,051$ & 0,172 & $\mathrm{I}(1)$ \\
\hline \multirow[t]{3}{*}{$(2000-2014)$} & IP & $-1,019$ & $-1,163$ & $-0,675$ & 0,2170 & $\mathrm{I}(1)$ \\
\hline & $\mathrm{TJ}$ & $-4,227^{\star}$ & $-4,146^{\star}$ & $-2,605^{\star}$ & $0,117^{\star}$ & $\mathrm{I}(0)$ \\
\hline & PI & $-1,819$ & $-1,899$ & $-9,806^{*}$ & 0,233 & $\mathrm{I}(1)$ \\
\hline Chile & $\mathrm{TC}$ & $-2,615$ & $-1,969$ & $-2,216$ & 0,126 & $\mathrm{I}(1)$ \\
\hline \multirow[t]{3}{*}{$(2000-2014)$} & IP & $-2,416$ & $-2,131$ & $-1,924$ & $0,192^{\star *}$ & $\mathrm{I}(1)$ \\
\hline & $\mathrm{TJ}$ & $-2,854$ & $-2,523$ & $-2,791$ & 0,138 & $\mathrm{I}(1)$ \\
\hline & PI & $-2,152$ & $-1,784$ & $-7,001^{\star}$ & 0,225 & $\mathrm{I}(1)$ \\
\hline Colômbia & $\mathrm{TC}$ & $-2,019$ & $-1,542$ & $-1,755$ & 0,994 & $\mathrm{I}(1)$ \\
\hline \multirow[t]{3}{*}{$(2000-2014)$} & IP & $-2,369$ & $-1,936$ & $-1,480$ & $0,3272^{\star}$ & $\mathrm{I}(1)$ \\
\hline & $\mathrm{TJ}$ & $-2,190$ & $-2,275$ & $-2,593$ & $0,086^{*}$ & $\mathrm{I}(1)$ \\
\hline & PI & $-2,120$ & $-2,115$ & $-2,311$ & $0,104^{*}$ & $\mathrm{I}(1)$ \\
\hline México & $\mathrm{TC}$ & $-3,383^{\star *}$ & $-3,841^{\star}$ & $-3,335^{\star * *}$ & $0,059^{*}$ & $\mathrm{I}(0)$ \\
\hline \multirow[t]{3}{*}{$(2000-2014)$} & IP & $-0,899$ & $-1,1126$ & $-2,218$ & $0,368^{*}$ & $\mathrm{I}(1)$ \\
\hline & $\mathrm{TJ}$ & $-3,064$ & $-1,424$ & $-3,137$ & 0,133 & $\mathrm{I}(1)$ \\
\hline & PI & $-3,075$ & $-2,970$ & $-6,583^{*}$ & 0,126 & $\mathrm{I}(1)$ \\
\hline Peru & $\mathrm{TC}$ & $-2,256$ & $-2,164$ & $-2,001$ & 0,141 & $\mathrm{I}(1)$ \\
\hline \multirow[t]{2}{*}{$(2000-2014)$} & IP & $-3,086$ & $-2,483$ & $-2,725$ & $-0,137^{\star \star}$ & $\mathrm{I}(1)$ \\
\hline & $\mathrm{TJ}$ & $-3,916^{\star *}$ & 1,583 & $3,851^{\star *}$ & $0,186^{\star *}$ & $\mathrm{I}(1)$ \\
\hline
\end{tabular}

Notas: PI, TC, IP, TJ, na ordem, produção industrial, taxa de câmbio, índice de preços e taxa de juros. $\left(^{*}\right),\left(^{* *}\right)$ e $\left({ }^{* * *}\right)$ significativos a $1 \%, 5 \%$ e $10 \%$, respectivamente.

Fonte: Elaboração própria.

O teste de cointegração de Johansen foi realizado tendo em vista os resultados previamente obtidos e como recomendado pela literatura, os quais estão ilustrados na Tabela 6. Esse teste permite inferir se a combinação linear entre as variáveis considerada é estacionária e, portanto, se há uma relação de longo prazo. Dessa forma, observa-se, por meio das estatísticas de traço e máximo autovalor, a rejeição da hipótese 
nula em um nível de significância de 5\%, o que implica a existência de pelo menos uma relação de cointegração para Brasil, Chile e México, duas para Peru e Colômbia. Tais conclusões validam a utilização do modelo do vetor correção de erro (VEC) e também são suportadas por Fonseca et al. (2013).

Tabela 6 - Resultados do teste de cointegração de Johansen

\begin{tabular}{|c|c|c|c|c|c|}
\hline País & Equações cointegradas & Traço & P-valor & Máximo autovalor & P-valor \\
\hline & $\mathrm{R}=0$ & 58,11 & 0,0041 & 31,22 & 0,0163 \\
\hline \multirow[t]{3}{*}{ Brasil } & $\mathrm{R} \leq 1$ & 26,89 & 0,1042 & 21,13 & 0,0500 \\
\hline & $\mathrm{R} \leq 2$ & 5,76 & 0,7232 & 5,69 & 0,6534 \\
\hline & $\mathrm{R}=0$ & 63,09 & 0,0010 & 33,89 & 0,0068 \\
\hline \multirow[t]{3}{*}{ Chile } & $\mathrm{R} \leq 1$ & 29,20 & 0,0584 & 15,28 & 0,2696 \\
\hline & $\mathrm{R} \leq 2$ & 13,92 & 0,0851 & 10,91 & 0,1584 \\
\hline & $\mathrm{R}=0$ & 89,47 & 0,0000 & 44,12 & 0,0002 \\
\hline \multirow[t]{3}{*}{ Colômbia } & $\mathrm{R} \leq 1$ & 45,35 & 0,0004 & 34,07 & 0,0005 \\
\hline & $\mathrm{R} \leq 2$ & 11,27 & 0,1952 & 7,47 & 0,4350 \\
\hline & $\mathrm{R}=0$ & 57,67 & 0,0046 & 33,43 & 0,0079 \\
\hline \multirow[t]{3}{*}{ México } & $\mathrm{R} \leq 1$ & 24,23 & 0,1905 & 16,04 & 0,2223 \\
\hline & $\mathrm{R} \leq 2$ & 8,19 & 0,4448 & 6,99 & 0,4896 \\
\hline & $\mathrm{R}=0$ & 77,78 & 0,0000 & 45,11 & 0,0001 \\
\hline \multirow[t]{2}{*}{ Peru } & $\mathrm{R} \leq 1$ & 32,67 & 0,0277 & 23,09 & 0,0261 \\
\hline & $\mathrm{R} \leq 2$ & 9,57 & 0,3150 & 5,78 & 0,6418 \\
\hline
\end{tabular}

Nota: resultados do Eviews 7.2.

Fonte: Elaboração própria.

Assim, estimou-se o modelo VEC, que mostra a relação de longo prazo entre a mudança na taxa de juros e seu efeito sobre a produção industrial, índice de preços e taxa de câmbio. Isso permite avaliar a eficácia da política monetária no regime de metas de inflação. Nesse caso, a taxa de juros de curto prazo é considerada uma variável endógena, uma vez que o estabelecimento de seu nível depende das expectativas sobre a própria taxa de juros e evolução das demais variáveis, em particular das mudanças no índice de preço. Desse modo, as estimativas dos coeficientes de ajustamento de longo prazo são ilustradas na Tabela 7. Nota-se que os parâmetros estimados da variável, que representa o nível de atividade, mostraram-se significativos, com exceção de Chile e México, para os quais foram estatisticamente iguais a zero. Os maiores valores, com sinal negativo, são encontrados em Colômbia e Brasil, com 16,34 e 12, 09, respectivamente. 
Os parâmetros estimados de velocidade de ajuste no longo prazo do índice de preços dos países considerados são estatisticamente significativos, com exceção do Chile $^{8}$. Esses indicadores variam na faixa de aproximadamente três a 11 para Brasil, Chile, Colômbia e México, e cerca de 30 para o Peru. Esse resultado vem corroborar a forte reação por parte das autoridades monetárias à mudança das expectativas inflacionárias via taxa de juros de curto prazo.

Tabela 7 - Estimação da função de longo prazo

\begin{tabular}{lcccc}
\hline País & Constante & PI & IP & TC \\
\hline \multirow{2}{*}{ Brasil } & 55,56 & $-12,098$ & 3,444 & $-3,020$ \\
& & $(-4,467)$ & $(5,636)$ & $(-4,575)$ \\
\hline \multirow{2}{*}{ Chile } & $-65,620$ & 5,679 & $-7,448$ & 6,332 \\
& & $(1,689)^{*}$ & $(-1,629)^{*}$ & $(4,326)$ \\
\hline \multirow{2}{*}{ Colômbia } & 105,746 & $-16,342$ & 11,433 & $-4,299$ \\
& & $(-6,696)$ & $(7,582)$ & $(-4,486)$ \\
\hline \multirow{2}{*}{ México } & $-2,21$ & $-0,117$ & 2,914 & $-0,156$ \\
& & $(-0,142)^{*}$ & $(6,357)$ & $(-0,519)^{*}$ \\
\hline \multirow{2}{*}{ Peru } & 28,196 & $-10,703$ & 30,701 & 12,072 \\
& & $(-3,332)$ & $(5,298)$ & $(3,688)$ \\
\hline
\end{tabular}

Notas: A estatística t encontra-se entre parênteses. ( ${ }^{*}$ Indica a ausência de significância estatística.

Fonte: Elaboração própria.

No que concerne aos coeficientes de ajuste de longo prazo da taxa de câmbio devido a inovações na taxa de juros, eles foram estatisticamente significativos para Brasil, Chile, Colômbia e Peru.

A trajetória função impulso-resposta sobre o nível de atividade, índice de preço e taxa de câmbio devido a mudanças na política monetária dos países da América Latina com regime de metas de inflação pode ser observada por meio da Figura 1. Em geral as inovações da taxa de juros de curto prazo provocam reações negativas sobre o nível de atividade em todas as economias analisadas. No entanto ocorre uma elevação inicial nesse indicador em Brasil, Chile, México e Peru, mas com respostas negativas a partir do segundo mês. Salienta-se que a queda do nível de atividade na economia brasileira tende a ser mais pronunciada. $\mathrm{Na}$ Colômbia, essa reação apresenta-se oscilatória e, em geral, sempre negativa. No Chile, as mudanças na taxa de juros implicam efeitos positivos mais elevados, sobre o nível de atividades, entre o primeiro e terceiro mês, e após o quinto mês esses impactos passam a ser nulos.

8 O p-value para o índice de preços no Chile é de $0,1051$. 
A resposta dos índices de preços à alteração da política monetária via taxa de juros tende a guardar forte semelhança entre a Colômbia e o Brasil. O resultado é uma redução imediata na taxa de variação do índice com pequenas mudanças no declive observadas nos meses segundo e quinto, ou seja, essas inovações implicam quedas relativamente rápidas nos índices de preços nesses países, o que ratifica a eficácia da política monetária no controle de inflação. Destaca-se que, para o Brasil, esse resultado somente foi obtido a partir de julho de 2003.

Os efeitos da política monetária sobre o índice de preço no México se dão com defasagem de um período, posteriormente eles provocam uma queda contínua até o quinto mês e, a partir disso, os preços tornam a subir, oscilando, mas retomando a trajetória de queda no nono período. Para o México somente foi possível avaliar a eficácia da política monetária no período mais recente, ou seja, a partir de junho de 2009. Na economia chilena, a resposta de uma mudança na taxa de juros da política monetária é uma elevação inicial dos preços e com redução contínua a partir do sexto período, após pequena oscilação.

Os resultados, contudo, de uma contração na política monetária, associados a uma elevação inicial da inflação, como ocorre no Chile, em particular, quando se considera o período de 2000 a 2013, no Brasil e no México, evidenciam o que a literatura trata como price puzzle 9 A correlação positiva entre um choque de taxa de juros nominal de curto prazo e a taxa de inflação tem recebido atenção por parte dos pesquisadores na área, pois não teria suporte na teoria econômica tradicional. Para Sims (1992), a explicação pode estar no problema da identificação dos modelos VAR, ou seja, as variáveis incluídas nesses modelos não incorporariam todo o conjunto de informação disponível pelo Banco Central para elaboração da política monetária ${ }^{10}$.

9 O termo foi tratado inicialmente por Sims (1992).

${ }^{10}$ Omoto (2006) indica a utilização de alguma medida de preço de commodity como opção, baseando-se no fato de que o price puzzle é originário de choques de oferta que afetam o nível de atividade da economia. 
Figura 1 - Função impulso-resposta na taxa de juros com um desvio padrão

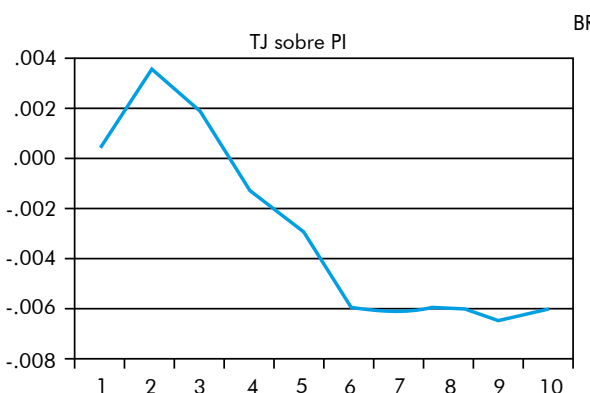
BRASIL
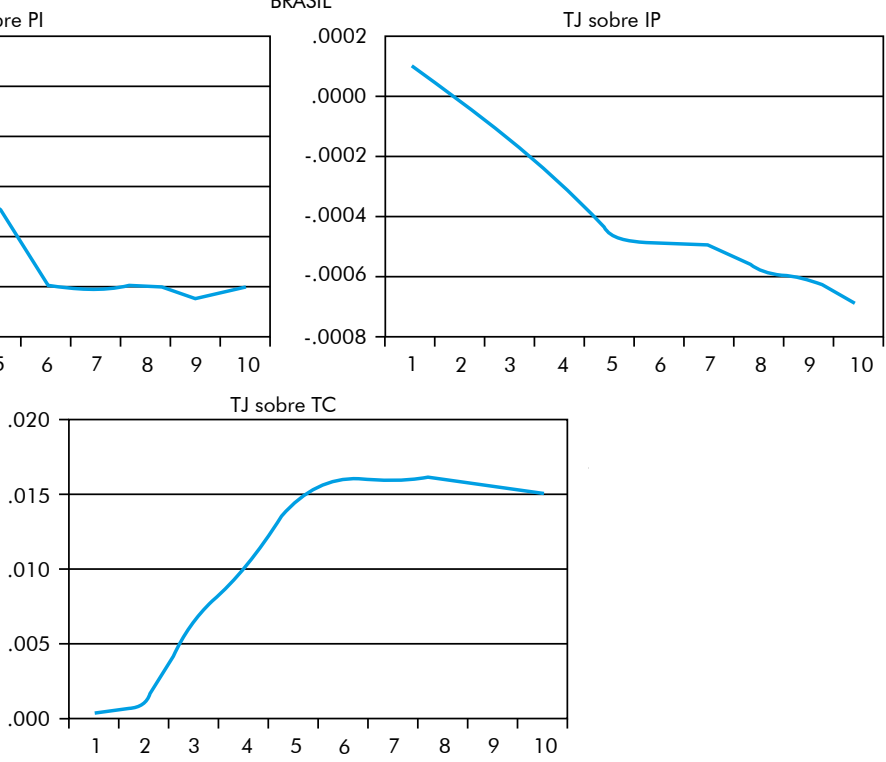

sobre TC 


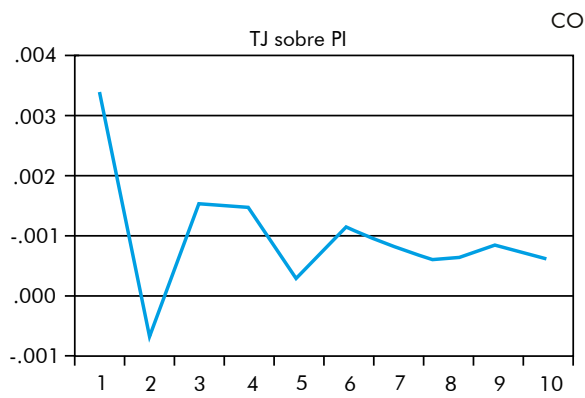

COLÔMBIA
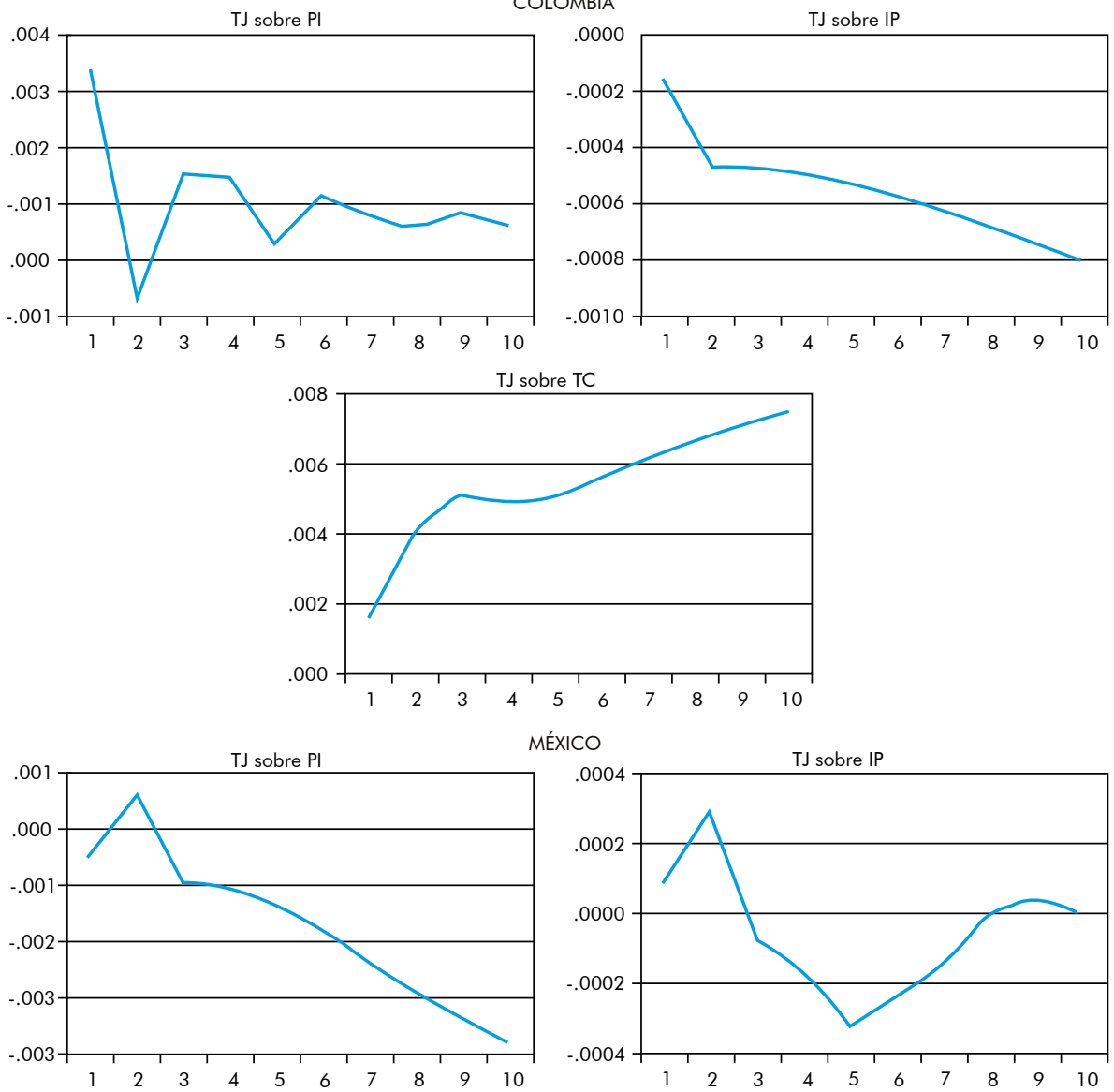

MÉXICO
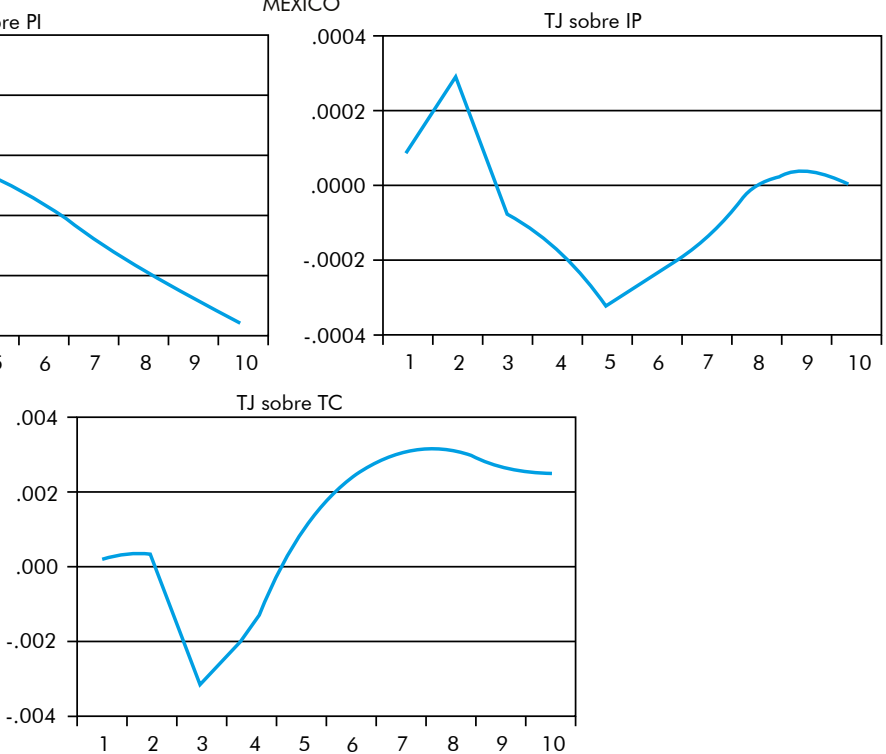


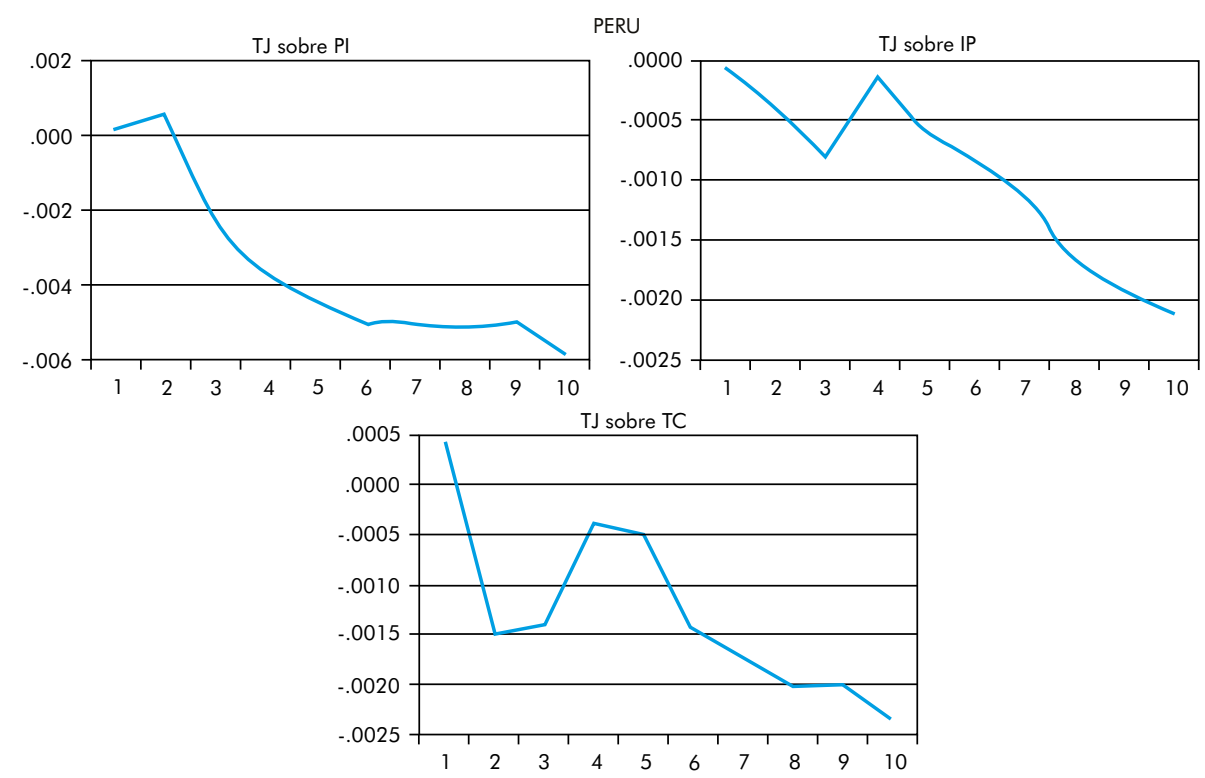

Nota: resposta de uma inovação de um desvio padrão de Cholesky. Para o Brasil, o período considerado foi a partir de jul. 2003, e para o México a partir de jun. 2009.

Fonte: Elaboração própria.

A outra explicação seria a de que uma contração da oferta monetária não antecipada pelos agentes econômicos operaria via outro mecanismo de transmissão da política monetária que é a elevação de custos de produção, como abordam Modenesi et al. (2012) e Fonseca et al. (2013). As empresas, em função do poder de mercado e das condições de demanda, tenderiam a repassar esses custos aos preços, provocando uma redução na oferta agregada e, em seguida, uma elevação na taxa de inflação. Assim, o efeito price puzzle surge pela defasagem do impulso da política monetária que inicialmente atua sobre os custos de produção, e somente mais tarde sobre a demanda agregada e o nível de preços.

As respostas de uma inovação na taxa de juros tendem a provocar movimentos distintos na taxa de câmbio, com tendências de depreciação para Brasil, México e Colômbia. Por outro lado, Peru e Chile apresentam tendência de apreciação da taxa de câmbio, após movimentos oscilatórios.

Em síntese, os resultados têm demostrado que o índice de preços tende a responder imediatamente e de forma oposta aos movimentos da taxa de juros. Essas evidências vêm ratificar a eficácia da política monetária no combate à inflação nos países da América Latina com metas de inflação. Tais achados são consistentes àqueles observados na literatura. A menor eficiência da política monetária, constatada ao longo do período de 2001 a 2013 no México, pode estar associada pela sua maior rigidez. O 
México foi único a utilizar um mecanismo de política monetária baseado em regulação da liquidez por meio de saldos monetários acumulados.

\section{CONCLUSÃO}

O sistema monetário de metas de inflação tem apresentado um papel essencial, em particular nos países de mercados emergentes, no sentido de redução a volatilidade tanto do produto como da taxa de inflação. Além disso, esse regime permitiu uma maior flexibilidade na taxa de câmbio com menores efeitos sobre a inflação advinda da desvalorização cambial. A transparência e a clareza das informações transmitidas pelos Bancos Centrais ao público, que fazem parte da operacionalização do sistema, implicaram numa diminuição significativa das incertezas dos agentes econômicos.

O principal propósito dos países da América Latina em adotar o arranjo de metas de inflação foi garantir um sistema financeiro sólido e uma inflação baixa e estável. Essa hipótese tem sido corroborada em todos eles. A média anual da taxa de inflação passou de 231,84\%, ao longo dos anos 1990, para 5,32\% no período de 2000 a 2013. Em geral ocorreu também uma redução na sua volatilidade, de 3,48 para 3,19, e um aumento da taxa de crescimento média anual do produto, de 3,37\% para 3,83 de um período para outro.

No que tange aos testes econométricos, os resultados mostram que não é possível rejeitar a hipótese da presença de raiz unitária no nível das séries estatísticas utilizadas. Já em sua primeira diferença, elas são estacionárias. Esse fato permitiu o uso do teste de cointegração de Johansen, que indicou a existência de pelo menos um vetor de cointegração para Brasil, Chile e México, e dois para Peru e Colômbia. Essa conclusão valida o emprego do modelo do vetor correção de erro (VEC), o qual produziu parâmetros estimados da velocidade de ajustamento no longo prazo do índice de preços, estatisticamente diferentes de zero para todos os países, com exceção do Chile. Tal fato ratifica forte reação por parte das autoridades monetárias à mudança na taxa de inflação via taxa de juros de curto prazo. Em geral, os coeficientes de ajuste de longo prazo do nível de atividade e da taxa de câmbio devidos a inovações na taxa de juros também foram estatisticamente significativos para a maioria dos países, mas com menor velocidade de ajuste.

A trajetória da função impulso-resposta devida às inovações da taxa de juros de curto prazo sobre índice de preço tem corroborado a eficácia da política monetária no combate à inflação em países da América Latina com metas de inflação. Para o Brasil e o México, esse fato foi observado no período mais recente, isto é, a partir de julho de 2003 e junho de 2009, respectivamente. 
Por fim, as evidências empíricas coletadas têm implicação política relevante para o conjunto de países da América Latina com metas de inflação. Contudo, essas conclusões devem ser qualificadas, porque a análise não levou em conta outras variáveis macroeconômicas por ausência de informações e pelo contexto mundial no período. Outra limitação do estudo refere-se à avaliação dos efeitos das expectativas inflacionárias num sistema de metas da inflação.

\section{REFERÊNCIAS BIBLIOGRÁFICA}

AGENOR, P-R.; SILVA, L. A. P. Inflation Targeting and financial stability: a perspective from the developing world. Banco Central do Brasil. Working Papers Series, n. 324, set. 2013.

AGUIRRE, H.; BURDISSO, T. Dangerous Liaisons? An empirical assessment of inflation targeting and exchange rate regimes. Working Paper, Banco Central de la República Argentina, n. 2008/39, 2008.

ARESTIS, P. Inflation targeting: a critical approach. Ensayos Economicos, Banco Central da República da Argentina, n. 68, jun. 2013.

BERNANKE, B. S.; MISHKIN, F. S. Inflation Targeting: a new framework for monetary policy? The Journal of Economic Perspectives, v. 11, n. 2, p. 97-116, spring, 1997.

BERNANKE, B. S.; WOODFORD, M. Inflation forecasts and monetary Policy. Journal of Money, Credit and Banking, v. 29, p. 653-684, 1997.

BIONDI, R. L.; TONETO, R. O desempenho dos países que adotaram o regime de metas inflacionárias: uma análise comparativa. Cadernos PROLAM/USP, São Paulo, ano 4, v. 2, p. 7-31, 2005.

BROTO, C. Inflation Targeting in Latin America: Empirical Analysis using GARCH Models. Economic Modelling, v. 28, p. 1424-34, may 2011.

CALANI, Maurício C.; COWAN, Kevin L.; GARCIA, Pablo S. Metas de inflación en economías financieramente estables: ¿un sistema suficientemente flexible? Economía Chilena, v. 13, n. 2, ago. 2010.

CAPISTRÁN, C.; RAMOS-FRANCIA, M. Does Inflation Targeting Affect the Dispersion of Inflation Expectations? Journal of Money, Credit and Banking, v. 42, p 113-134, feb. 2010.

FAZIO, D. M.; TABAK, B. M.; CAJUEIRO, D. O. Inflation targeting and banking system soundness: a comprehensive analysis. Working Papers Series, Banco Central do Brasil, n. 347, feb. 2014.

FONSECA, M. R. R.; PERES, S. C.; ARAÚJO, E. C. Regime de metas de inflação: análise comparativa e evidências empíricas para países emergentes selecionados: In: ENCONTRO DE ECONOMIA DA REGIÃO SUL - ANPEC SUL, 16., Curitiba, Paraná, 13-14 jun. 2013. Anais... ANPEC: Curitiba, 2013. Disponível em: <http://www.anpec.org.br/sul/2013>. Acesso em: 03 mar. 2015.

FRAGA, A.; GOLDFAJN, I.; MINELLA, A. Inflation targeting in emerging market economies. Working Paper Series, Banco Central do Brasil, n. 76, jun. 2003. 
FREITAS, M. C. P. "Regime de metas de inflação em perspectiva comparada". In: BIASOTO Jr.; G. et al. Panorama da economia internacional e brasileira: dinâmica e impactos da crise global. São Paulo: Edições Fundap, 2009, p. 98-112. Disponível em: <http://www.fundap. sp.gov.br>. Acesso em: 14 mar. 2015.

GONÇALVES, C. E.; SALLES, J. Inflation targeting in emerging economies: what do data say? Journal of Development Economies, v. 1/2, n. 85, p. 312-318, feb. 2008.

GREENE, W. H. Econometric Analysis. 3. ed. Upper Saddle River: Prentice Hall, 1997.

HAMANN, F.; HOFSTETTER, M.; URRUTIA, M. Inflation Targeting in Colombia, 2002-2011. Borradores de Economía, Banco de la República, n. 818, 2014.

HAMILTON, J. D. Time Series Analysis. Princeton: Princeton University Press, 1994.

HAMMOND, G.. State of the art of inflation targeting - 2012. Centre for Central Banking Studies, Bank of England, Feb. 2012.

HEBBEL-SCHMIDT, K. Política monetaria y mecanismos de transmisión bajo metas de inflación. División de Investigaciones Económicas del Departamento de Estudios del Banco Central de Chile, 2003.

HEBBEL-SCHMIDT, K. Inflation targeting twenty years on: where, when, why, with what effects, what lies ahead? Working Paper, Catholic University of Chile, n. 360, oct. 2009.

IMF - INTERNATIONAL MONETARY FUND. Annual Report on Exchange Arrangements and Exchange Restrictions. Publication Services, Washington, IMF, oct. 2013.

IMF - INTERNATIONAL MONETARY FUND. World Economic Outlook Adjusting to Lower Commodity Prices. Washington, D.C.: IMF, oct. 2015.

MASSON, P. R; SAVASTANO, M. A.; SHARMA, A. Can inflation targeting be a framework for monetary policy in developing countries? Finance \& Development, FMI, v. 35, n. 1, p. 34-37, Mar 1998.

MISHKIN, F. S. International experience with monetary policy regimes. Journal of Monetary Economics, v. 43, p. 579-606, 1999.

MISHKIN F. De metas monetárias a metas de inflación: Lecciones de los Países Industrializados. Conferencia del Banco de México, Estabilización y Política Monetaria: La Experiencia Internacional, 2000. p. 113-159.

MISHKIN, F. S.; SCHMIDT-HEBBEL, K. Does inflation targeting make a difference? NBER Working Paper, n. 12876, Jan. 2007.

MODENESI, A; PIRES-ALVES, C. C; MARTINS, M. N. Mecanismo de Transmissão da Política Monetária: a importância dos fatores microeconômicos. Oikos, Rio de Janeiro, v. 11, p. 203 216, 2012.

OMOTO, Kátia H. Os efeitos dos choques de política monetária sobre atividade econômica e os preços no Brasil. Dissertação (Mestrado em Economia) - Pós-Graduação em Economia, Universidade Estadual de Maringá, Maringá, Paraná, 2006.

OSSIO, P. M.; ALARCÓN, D. M. ¿Éxito o fracaso de metas explícitas de inflación?: Analizando la respuesta al repunte inflacionario de 2007-2008. Revista de Análisis, v. 13, p. 91-117, 2010. 
PESAM. H.; SHIN, Y. Generalized Impulse Response Analysis in linear Multivariate Models. Economic Letters, v. 58, p. 17-29, 1998.

SIMS, C. Interpreting the macroeconomic time series facts: the effects of monetary policy. European Economic Review, v. 36, p. 975-1000, 1992.

SVENSSON, L. E. O. Inflation forecast targeting: implementing and monitoring inflation targets. European Economic Review, v. 41, p. 1111-1146, 1997.

TRICHES, D. Economia política do Mercosul e aspectos monetários e cambiais e o Euro em perspectiva. Caxias do Sul: Educs, 2003.

\section{ANEXO}

Tabela A1 - Taxa média e variabilidade das variáveis macroeconômicas selecionadas dos países da América Latina no período de 1990 a 2013

\begin{tabular}{|c|c|c|c|c|c|c|}
\hline \multirow{2}{*}{ País } & \multicolumn{2}{|c|}{ Taxa de desemprego } & \multicolumn{2}{|c|}{ Taxa de Juros } & \multicolumn{2}{|c|}{ Taxa de Câmbio } \\
\hline & Média (\%) & Variab. & Média (\%) & Variab. & Média (\%) & Variab. \\
\hline Brasil & 5,59 & 1,17 & 2646,71 & 4900,58 & 0,67 & 0,63 \\
\hline Chile & 7,32 & 1,20 & - & - & 403,85 & 57,06 \\
\hline Uruguai & 9,90 & 1,31 & 27,16 & 9,88 & 6,08 & 3,61 \\
\hline México & 3,65 & 1,24 & 28,11 & 13,35 & 5,61 & 2,79 \\
\hline Peru & 8,15 & 1,31 & 14,50 & 3,32 & 2,01 & 0,99 \\
\hline Colômbia & 7,31 & 2,51 & 25,68 & 6,23 & 987,52 & 374,73 \\
\hline Paraguai & 5,56 & 1,37 & 18,02 & 3,73 & 5,52 & 1,17 \\
\hline $\begin{array}{l}\text { Média } \\
\text { 1990-1999 }\end{array}$ & 6,78 & - & 460,03 & - & 201,61 & - \\
\hline Brasil & 8,75 & 2,41 & 14,34 & 4,64 & 2,22 & 0,47 \\
\hline Chile & 8,53 & 1,53 & 4,61 & 2,35 & 559,71 & 70,15 \\
\hline Uruguai & 10,67 & 3,99 & 14,58 & 21,54 & 21,38 & 4,66 \\
\hline México & 4,00 & 1,03 & 7,84 & 3,48 & 11,35 & 1,36 \\
\hline Peru & 8,47 & 0,86 & 4,29 & 2,40 & 3,14 & 0,33 \\
\hline Colômbia & 12,33 & 1,75 & 6,69 & 2,48 & 2192,62 & 322,87 \\
\hline Paraguai & 6,70 & 1,47 & 7,29 & 4,22 & 6,54 & 1,63 \\
\hline $\begin{array}{l}\text { Média } \\
\text { 2000-2013 }\end{array}$ & 8,49 & - & 8,52 & - & 399,56 & - \\
\hline
\end{tabular}

Nota: Antes da meta refere-se à década de 1990, e após metas aos anos de 2000 a 2014.

Fonte: IMF (2013). 


\section{Quadro A1 - Resumo dos estudos recentes de metas de inflação e modelos aplicados para os países da América Latina}

\begin{tabular}{|c|c|c|c|c|}
\hline $\begin{array}{l}\text { Aguirre e } \\
\text { Burdisso } \\
(2005)\end{array}$ & $\begin{array}{c}\text { 1990-2006 } \\
\text { (22 países com metas } \\
\text { de inflação) }\end{array}$ & $\begin{array}{c}\text { Dados de } \\
\text { Painel }\end{array}$ & Dados anuais & $\begin{array}{l}\text { Há endogeneidade potencial entre o desempenho da } \\
\text { inflação e a escolha do regime cambial. A taxa de } \\
\text { câmbio desempenha um papel essencial no mecanismo } \\
\text { de transmissão de monetária em economias pequenas e } \\
\text { abertas, e é um determinante das expectativas de } \\
\text { inflação. }\end{array}$ \\
\hline $\begin{array}{l}\text { Biondi e } \\
\text { Toneto } \\
(2005)\end{array}$ & $\begin{array}{c}\text { 1996-2004 } \\
\text { (20 países com metas } \\
\text { de inflação) }\end{array}$ & $\begin{array}{c}\text { Análise } \\
\text { qualitativa e } \\
\text { Estatísticas } \\
\text { descritivas }\end{array}$ & $\begin{array}{c}\text { Dados } \\
\text { mensais }\end{array}$ & $\begin{array}{l}\text { Países com regime de metas de inflação experimentam } \\
\text { uma menor variação nas taxas de inflação e menores } \\
\text { taxas médias de crescimento real do produto. Os custos } \\
\text { de convergência da taxa de inflação para a metas são } \\
\text { ainda maiores em termos de baixo crescimento do } \\
\text { produto para os países em desenvolvimento. }\end{array}$ \\
\hline $\begin{array}{l}\text { Calani et al. } \\
(2010)\end{array}$ & $\begin{array}{l}\text { Jan./2007-Ago./2008 } \\
\text { (Austrália, Brasil, Chile, } \\
\text { Colômbia, Coreia do } \\
\text { Sul, Indonésia, México, } \\
\text { Nova Zelândia e Peru) }\end{array}$ & $\begin{array}{c}\text { Estimação } \\
\text { econométrica }\end{array}$ & $\begin{array}{l}\text { Dados } \\
\text { diários }\end{array}$ & $\begin{array}{l}\text { Existência de heterogeneidade nas medidas das políticas } \\
\text { monetárias e sua eficácia, mas obtiveram êxito em } \\
\text { reduzir as tensões nos mercados monetário e cambial. A } \\
\text { metas de inflação contribuíram para manter a } \\
\text { estabilidade de preços. }\end{array}$ \\
\hline $\begin{array}{l}\text { Fonseca et al. } \\
(2013)\end{array}$ & $\begin{array}{l}\text { Jan./2000-Jum./2012 } \\
\text { (África do Sul, Brasil, } \\
\text { Chile, Coreia do Sul, } \\
\text { Colômbia, México). }\end{array}$ & $\begin{array}{c}\text { Testes de raiz } \\
\text { unitária, Teste } \\
\text { de Granger e } \\
\text { VEC. }\end{array}$ & $\begin{array}{c}\text { Dados } \\
\text { mensais }\end{array}$ & $\begin{array}{c}\text { Os regimes de metas de inflação mais flexíveis como os } \\
\text { de Âfrica do Sul, Chile, Colômbia, Coreia do Sul são } \\
\text { relativamente mais eficazes no combate à inflação do } \\
\text { que os regimes mais rígidos, como os de Brasil e } \\
\text { México. }\end{array}$ \\
\hline $\begin{array}{l}\text { Fraga et al. } \\
(2003)\end{array}$ & $\begin{array}{l}\text { Jan.1997-Fev.2002 } \\
\text { (20 Países) }\end{array}$ & $\begin{array}{c}\text { Decomposição } \\
\text { da Variância }\end{array}$ & $\begin{array}{c}\text { Dados } \\
\text { mensais }\end{array}$ & $\begin{array}{c}\text { Regime de metas de inflação em economias de mercado } \\
\text { emergentes obtiveram êxito em reduzir a volatilidade do } \\
\text { produto, inflação, taxa de juros e taxa de câmbio, mas } \\
\text { ainda assim se mantiveram acima dos países } \\
\text { desenvolvidos. }\end{array}$ \\
\hline $\begin{array}{l}\text { Gonçalves e } \\
\text { Salles } \\
(2008)\end{array}$ & $\begin{array}{l}\text { 1980-2005 } \\
\quad(36 \text { Países de } \\
\text { economias de mercado } \\
\text { emergentes, } 13 \text { com } \\
\text { metade inflação) }\end{array}$ & $\begin{array}{c}\text { Estimação } \\
\text { econométrica } \\
\text { da volatilidade }\end{array}$ & $\begin{array}{c}\text { Dados } \\
\text { mensais }\end{array}$ & $\begin{array}{l}\text { Sistema de metas de inflação tem tido resultados } \\
\text { favoráveis em reduzir a inflação e a volatilidade do } \\
\text { produto e, quando comparado com regime monetário } \\
\text { alternativo, tem mostrado um desempenho econômico } \\
\text { superior. }\end{array}$ \\
\hline $\begin{array}{l}\text { Hamann et al. } \\
(2014)\end{array}$ & $\begin{array}{l}\text { Jan./2002- jun./2012 } \\
\text { (Colômbia) }\end{array}$ & $\begin{array}{l}\text { Economia } \\
\text { Bayesiana, } \\
\text { Regra de Taylor } \\
\text { e Intervenção } \\
\text { no mercado de } \\
\text { Câmbio }\end{array}$ & $\begin{array}{c}\text { Dados } \\
\text { mensais }\end{array}$ & $\begin{array}{l}\text { Taxa de câmbio real tem pouco efeito sobre o nível de } \\
\text { atividades econômicas, e a inflação se manteve imune às } \\
\text { mudanças na taxa de câmbio nominal. A consolidação } \\
\text { das metas de inflação tem sido positiva em manter taxa } \\
\text { de inflação estável, e sobre as atividades econômicas, } \\
\text { taxa de câmbio e estabilidade financeira. }\end{array}$ \\
\hline
\end{tabular}

Fonte: Elaboração própria. 


\section{ERRATA}

Na página 1, onde se lia:

"Divanildo Triches Triches"

Leia-se:

"Divanildo Triches"

Nas páginas 2 a 25, onde se lia:

“TRICHES, D. T.; FIORENTIN, G. P. Avaliação do regime de metas de inflação nos países da américa latina entre 2001 e 2014"

Leia-se:

“TRICHES, D.; FIORENTIN, G. P. Avaliação do regime de metas de inflação nos países da américa latina entre 2001 e 2014 ”

Rev. Econ. Contemp. (2018) 22(3): e1822222 